\title{
O ENSINO DE REDES DE COMPUTADORES USANDO APRENDIZAGEM BASEADA EM PROJETOS E A TEORIA DA APRENDIZAGEM SIGNIFICATIVA
}

\author{
Teaching Computer Networks through the Integration of Project-Based Learning with \\ the Meaningful Learning Theory
}

\author{
Marcos Juares Vissoto Corino ${ }^{1}$ \\ Silvia de Castro Bertagnolli ${ }^{2}$ \\ Marcelo Augusto Rauh Schmitt ${ }^{3}$
}

\begin{abstract}
Resumo: O presente artigo tem como objetivo apresentar como a Aprendizagem Baseada em Projetos pode ser integrada com a teoria da aprendizagem significativa de Ausubel, visando ao ensino de conteúdos da disciplina de redes de computadores. Para o seu desenvolvimento, foram selecionados como procedimentos metodológicos a pesquisa bibliográfica, a pesquisa documental e a pesquisa-ação. As atividades vinculadas à pesquisa-ação foram realizadas com 14 estudantes do curso Técnico de Informática subsequente ao Ensino Médio do Instituto Federal de Educação, Ciência e Tecnologia do Rio Grande do Sul, Campus Veranópolis. Durante essas atividades, os dados foram coletados usando três instrumentos: dois questionários com perguntas fechadas, um na primeira aula para identificar os conhecimentos prévios dos estudantes e o outro após a abordagem pedagógica proposta ter sido conduzida para determinar se houve ou não evolução nos conhecimentos dos estudantes; e um terceiro questionário avaliativo da atividade, com perguntas abertas e fechadas, para identificar aspectos que deveriam ser aprimorados na experiência de aprendizagem. Como resultado percebeu-se que essa integração proposta tem potencial para promoção da aprendizagem, pois contou com a participação ativa dos estudantes nas atividades práticas realizadas em sala de aula. Além disso, os estudantes relataram que a experimentação possibilitou desenvolver a criatividade, a investigação científica e a troca de conhecimento entre os pares. Por último, foi possível concluir que, com planejamento adequado, professores podem utilizar Aprendizagem Baseada em Projetos para promover aprendizagem significativa na área das redes de computadores.
\end{abstract}

Palavras-chave: Ensino de Redes de Computadores. Aprendizagem significativa. Aprendizagem baseada em projetos.

Abstract: This paper aims to report how Project-Based Learning may be integrated with Ausubel's theory of meaningful learning, to teach the contents of the subject of computer networks. Bibliographic, documentary and action research were the methodological tools used

\footnotetext{
${ }^{1}$ Mestre em Informática na Educação - Mestrado Profissional em Informática na Educação. Instituto Federal de Educação, Ciência e Tecnologia do Rio Grande do Sul - Campus Porto Alegre - RS / Brasil. E-mail: marcos.corino@veranopolis.ifrs.edu.br. Orcid: https://orcid.org/0000-0002-4739-2019.

2 Doutora em Computação. Professora do Mestrado Profissional em Informática na Educação. Instituto Federal de Educação, Ciência e Tecnologia do Rio Grande do Sul - Campus Porto Alegre - RS / Brasil. E-mail: silvia.bertagnolli@poa.ifrs.edu.br. Orcid: https://orcid.org/0000-0001-7495-6636.

${ }^{3}$ Doutor em Informática na Educação. Professor do Mestrado Profissional em Informática na Educação do Instituto Federal de Educação, Ciência e Tecnologia do Rio Grande do Sul - Campus Porto Alegre - RS / Brasil. E-mail: marcelo.schmitt@poa.ifrs.edu.br. Orcid: https://orcid.org/0000-0003-1290-5029.
} 
to accomplish the objective. The activities related to the action research were carried out with 14 students of the high school program in Technical Studies of Informatics of the Instituto Federal de Educação, Ciência e Tecnologia do Rio Grande do Sul, campus Veranópolis. During these activities, data were collected using three instruments: one closed-ended questions form to assess students' previous knowledge; other closed-ended questions form to assess students' knowledge after the activities' and one opened-ended and closed-ended questions form to identify aspects that should be improved in the learning experience. As a result, it was noticed that this proposed integration has learning potential as it had the active participation of students in practical activities performed in the classroom. Besides that, the students reported that the experimentation helped the development of skills like creativity, scientific research and the exchange of knowledge among peers. Finally, it was possible to conclude that, with adequate planning, teachers can use Project-Based Learning to produce meaningful learning in the field of computer networks.

Keywords: Computer Networks Teaching. Meaningful learning. Project-based learning.

\section{Introdução}

Com o advento da rede mundial de computadores, a tecnologia passou a ser usada em todas as áreas do conhecimento e também na realização de tarefas simples, tais como criar um post em uma rede social, até a algumas mais complexas, tais como realizar compras em lojas virtuais ou pagamentos no home banking. De forma semelhante, a área educacional foi fortemente influenciada pelas Tecnologias Digitais da Informação e da Comunicação (TDICs). Elas acabaram sendo empregadas em práticas pedagógicas e nos processos e estilos de aprendizagem. O uso eficiente dos recursos tecnológicos exige dos sujeitos um perfil diferenciado, em que não basta apenas estar alfabetizado digitalmente, é necessário ter competência digital e as habilidades necessárias para atuar no século XXI (TAROUCO, 2018).

Conforme argumentam Coll e Monero (2010), a sociedade contemporânea exige que os indivíduos possuam habilidades tecnológicas, a capacidade de construir relações interpessoais e de resolver problemas de forma colaborativa. Os atuais estudantes deverão ter capacidade de adaptação e improvisação frente a situações inesperadas às quais precisem responder (RESNICK, 2007). Neste sentido, para obter-se sucesso na sociedade da criatividade, o aluno precisa "aprender a pensar de forma criativa, planejar sistematicamente, analisar criticamente, trabalhar em colaboração, comunicar-se claramente, projetar iterativamente e aprender continuamente" (RESNICK, 2007, p. 18). Geralmente, as atividades realizadas em sala de aula não apoiam essas habilidades de aprendizagem, restringindo o desenvolvimento criativo dos estudantes. Neste contexto, Campos (2017) sustenta que a adoção de metodologias de aprendizagem ativas pode favorecer significativamente o amadurecimento dessas habilidades.

As metodologias ativas, além do suporte ao ensino, são eixos estruturantes de uma aprendizagem criativa, crítica, empreendedora, personalizada e compartilhada, que favorecem a aprendizagem colaborativa e a comunicação entre os alunos, pois permite a troca de informações, o trabalho em conjunto para a resolução de desafios e a elaboração de projetos (BACICH; MORAN, 2018). As metodologias ativas colocam o aluno como protagonistas do seu processo de aprendizagem, sendo fundamental o seu comprometimento, sua participação e a sua reflexão durante as etapas da aprendizagem, pois é ele que deve experimentar, desenvolver e criar com a orientação e o acompanhamento do professor (BACICH; MORAN, 2018). Nesse modelo, o professor atua como mediador da aprendizagem, mostrando caminhos e possibilidades que o estudante pode percorrer (LEAL; MIRANDA; CASA NOVA, 2017). 
Quando os alunos assumem o papel de protagonistas de seu processo de aprendizagem, eles aprimoram o relacionamento com os pares, aprendem a se comunicar com mais êxito tanto na forma escrita quanto na oralidade, e alcançam aptidão para resolver problemas e experimentar circunstâncias que demandam a tomada de decisão, o que resulta no desenvolvimento da autonomia no pensar e no atuar. Uma das metodologias ativas mais adotadas é a Aprendizagem Baseada em Projetos (ABP), uma vez que ela promove o diálogo sobre o que e como fazer, com o objetivo de contribuir para a aprendizagem dos estudantes, usando um projeto como seu elemento norteador.

Além de utilizar a aprendizagem baseada em projetos, a prática pedagógica apresentada neste trabalho utilizou os principais conceitos vinculados à teoria da aprendizagem significativa (AUSUBEL, 2000), a qual estabelece que o aspecto mais importante para a aprendizagem cognitiva é aquilo que o aprendiz já sabe, ou seja, seus conhecimentos prévios. Para o autor, a partir de ideias prévias relevantes que estão na estrutura cognitiva e mental do aprendiz ancoram os novos conhecimentos (AUSUBEL, 2000). Em resumo, o estudante consegue aprender ou adquirir conhecimentos através da ancoragem, ou seja, a aprendizagem ocorre quando a nova informação interage com os conhecimentos prévios (subsunçores) presentes na estrutura cognitiva do aprendiz (MOREIRA et al., 2000).

No contexto deste trabalho, optou-se por integrar a aprendizagem baseada em projetos com a teoria da aprendizagem significativa no Ensino de Redes de Computadores (ERC). Isso porque era necessário reconhecer os conhecimentos prévios dos estudantes para, usando esses subsunçores, agregar novos conhecimentos de redes de computadores nas suas estruturas cognitivas. De modo a favorecer a aquisição do conhecimento, percebeu-se a necessidade de conduzir a experiência de aprendizagem com algum tipo de tecnologia. Isso porque, como argumentam Bacich e Moran (2018), as tecnologias impulsionam uma aprendizagem criativa, crítica, empreendedora, personalizada e compartilhada. Várias tecnologias foram adotadas para executar o presente trabalho, porém o uso de robótica educacional foi essencial para o desenvolvimento das habilidades técnicas e tecnológicas dos participantes da pesquisa.

A Robótica Educacional (RE) foi usada porque tem a capacidade de representar os problemas do cotidiano, proporcionando um contexto mais significativo e motivador. Ela "permite situações de ensino e aprendizagem, capazes de propiciar uma efetiva integração de conceitos matemáticos com fenômenos físicos, sensores, motores e programação" (COSTA JUNIOR, 2017, p. 28). Além desses fatores, a RE foi selecionada para ser utilizada neste trabalho devido às características dos participantes: alunos vinculados a um curso técnico que precisam articular os conhecimentos teóricos aos práticos para exercer sua profissão.

Para o desenvolvimento da experiência relatada por este trabalho, que tem origem na pesquisa conduzida por Corino (2019), foram selecionados como procedimentos metodológicos a pesquisa bibliográfica, a pesquisa documental e a pesquisa-ação. As duas primeiras permitiram estabelecer a abordagem pedagógica utilizada e identificar os conteúdos de redes mais trabalhados nos cursos de informática do Instituto Federal de Educação, Ciência e Tecnologia do Rio Grande do Sul (IFRS), e usando as orientações constantes no Catálogo Nacional de Cursos Técnicos (CNCT) do Ministério da Educação (MEC) (MEC, 2016). Já as atividades da pesquisa-ação foram realizadas com 14 estudantes do curso Técnico de Informática subsequente ao Ensino Médio, do IFRS - campus Veranópolis. Durante essas atividades, os dados foram coletados usando três instrumentos: (i) questionário com perguntas fechadas aplicado na primeira aula para identificar os conhecimentos prévios; (ii) questionário com questões fechadas após aplicar a estratégia pedagógica, com o objetivo de determinar se houve ou não evolução nos conhecimentos dos estudantes; (iii) questionário avaliativo com 
perguntas abertas e fechadas para identificar aspectos que deveriam ser aprimorados na experiência de aprendizagem.

$\mathrm{O}$ artigo prossegue organizado da seguinte forma: seções 2, 3 e 4 apresentam alguns pressupostos teóricos vinculados ao trabalho. A seção 5 detalha os procedimentos metodológicos empregados, os instrumentos usados e suas relações com a aprendizagem. A seção 6 relata como a aprendizagem baseada em projetos foi correlacionada à teoria da aprendizagem significativa, destacando alguns detalhes da experimentação realizada. A seção 7 apresenta os resultados obtidos e algumas discussões pertinentes. E, por fim, a seção 8 descreve as conclusões obtidas com a pesquisa.

\section{Teoria da aprendizagem significativa}

A teoria da aprendizagem significativa, desenvolvida por David Ausubel na década de 1960, estabelece que se fosse possível determinar um único aspecto como o mais importante para a aprendizagem cognitiva, esse seria aquilo que o aprendiz já sabe. Para Ausubel (2000), o conhecimento é significativo por definição, pois trata-se do resultado significativo de um processo psicológico cognitivo que envolve a interação entre ideias prévias relevantes da estrutura cognitiva particular do aprendiz e sua estrutura mental para aprender ou para adquirir e reter conhecimentos. Assim, a aprendizagem ocorre quando a nova informação interage com os conhecimentos prévios presentes na estrutura cognitiva do aprendiz, que são definidos como subsunçores (MOREIRA et al, 2000).

Quando a aprendizagem é significativa, o novo conhecimento ancora-se em conceitos e ideias relevantes já existentes na estrutura cognitiva do aprendiz, sendo que os novos conceitos são ligados e assimilados a conceitos mais gerais e inclusivos. Como resultado desse processo de ancoragem, ocorre a modificação do subsunçor que adquire novos significados ou maior estabilidade cognitiva (MOREIRA, 1999).

A aprendizagem se expressa através do desenvolvimento da estrutura cognitiva do sujeito quando ocorre a agregação de novos conhecimentos a ela. De acordo com o tipo de relacionamento entre os subsunçores e as novas ideias, o processo de aprendizagem pode variar de mecânico a significativo. A aprendizagem significativa ocorre quando "o significado do novo conhecimento vem da interação com algum conhecimento especificamente relevante já existente na estrutura cognitiva do aprendiz com um certo grau de estabilidade e diferenciação" (MOREIRA, 2016, p. 31).

Ausubel (2000) estabelece que, para a aprendizagem ocorrer de forma significativa, essa interação entre conhecimentos prévios e as novas ideias deve ocorrer de forma não-literal e não-arbitrária. $\mathrm{O}$ aspecto não-literal quer dizer que o conceito assimilado à estrutura cognitiva é a essência do novo conhecimento e não as palavras exatas que o define (MOREIRA, 1997). Já a não arbitrariedade implica a existência de uma relação lógica, plausível e clara entre o novo conhecimento e os presentes na estrutura cognitiva do aprendiz. O mesmo conceito ou proposição pode ser apresentado em linguagem sinônima e transmitir exatamente o mesmo significado ao aprendiz (AUSUBEL, 2000).

Embora deva-se buscar a aprendizagem significativa, existem circunstâncias em que a aprendizagem mecânica é necessária. No processo de aprendizagem mecânico o conhecimento é armazenado com pouca ou nenhuma interação com algum subsunçor (AUSUBEL, 2000). Dessa forma, o novo conhecimento não se agrega à estrutura cognitiva, tampouco a modifica. O aluno não atribui significado e apenas armazena a informação recebida, o que pode ser chamado de memorização. Ausubel (2000) não estabelece a distinção entre essas duas formas 
de conhecer como antagônicas, mas sim argumenta que elas fazem parte de um processo contínuo. Para Moreira (2016), "não se deve pensar que a aprendizagem é significativa ou mecânica", ou seja, a aprendizagem inicialmente mecânica pode, aos poucos, se tornar significativa.

É importante ressaltar que essas formas de aprendizagem não sejam confundidas com a aprendizagem por descoberta ou por recepção. Na aprendizagem por recepção o novo conhecimento é apresentado, independente do meio, na sua forma final, sem propor qualquer tipo de descoberta por parte do aprendiz, exigindo apenas o armazenamento e a recuperação do significado quando necessário. Por outro lado, na aprendizagem por descoberta o significado principal deve ser percebido de forma autônoma antes de ser relacionado à estrutura cognitiva, ou seja, o aprendiz deve descobrir por si mesmo, "criando proposições que representem soluções para os problemas colocados ou passos sucessivos com vista a resolução dos mesmos" (AUSUBEL, 2000, p. 112). Assim, segundo Moreira (2016), tanto a aprendizagem por descoberta quanto por recepção pode ser significativa ou mecânica. O que determina a forma de aprendizagem não é como o aprendiz tem acesso ao novo conhecimento, mas sim como ele os relaciona à sua estrutura cognitiva.

A aprendizagem subordinada, ou subsunção, ocorre quando o novo conhecimento obtém significado por meio de relação inclusiva, substantiva e não-arbitrária, aos subsunçores já existentes na estrutura cognitiva. Caso a nova ideia seja compreendida como um exemplo, uma validação ou fundamento da ideia subsunçora, a aprendizagem subordinada é dita derivativa; se essa nova ideia for um acréscimo, formação, transformação, delineamento do subsunçor, é considerada correlativa (AUSUBEL, 2000).

Nesse contexto, pode-se alcançar a aprendizagem de forma subordinada derivativa, pois o aluno deve ser capaz de entender os conceitos expostos como um exemplo dos conceitos trabalhados nas disciplinas de redes. Outrossim, esse entendimento pode dar-se por meio da superordenação, já que os conceitos passam a fazer parte de um universo que o aluno antes entendia apenas como do computador, e agora vê como uma série de possibilidades.

Segundo Ausubel (2000), conforme um novo conhecimento adquire significados através da interação com o conhecimento prévio, ele vai se modificando, pois ganha novos significados. Esse processo resulta na diferenciação progressiva do conceito subsunçor, tornando-o mais diferenciado, processo típico da aprendizagem significativa subordinada (MOREIRA, 2012). Ao planejar uma unidade de aprendizagem segundo o princípio de diferenciação progressiva, inicia-se pelas ideias mais gerais e inclusivas da disciplina. Em seguida, elas vão sendo progressivamente diferenciadas em seus detalhes, suas particularidades e nível de dificuldade. Essa sequência programática corresponde à sequência natural de aquisição e o refinamento do conhecimento quando da exposição do aprendiz a uma área de conhecimento até então desconhecida, ou a um braço desconhecido de um conjunto de conhecimentos familiares. Isso ocorre porque, é mais fácil para o aprendiz aprender "aspectos diferenciados de um todo, anteriormente apreendido e mais inclusivo, do que formular o todo inclusivo a partir das partes diferenciadas anteriormente aprendidas" (AUSUBEL, 2000, p. 166).

Já o processo de reconciliação integrativa ou o planejamento do material pedagógico deve também "explorar relações entre ideias, apontar similaridades e diferenças relevantes, reconciliando discrepâncias reais ou aparentes" (MOREIRA et al., 2000, p. 131). Essa recombinação de ideias estabelecidas na estrutura cognitiva, que podem ser percebidas como relacionadas e reorganizadas, vai adquirindo, assim, novos significados, que são produto da aprendizagem superordenada ou combinatória (MOREIRA, 1999). 
Esses dois conceitos abordados pela teoria de aprendizagem significativa de Ausubel (2000) são muito importantes no processo de aquisição do conhecimento. Isso porque a diferenciação progressiva e a reconciliação integrativa são processos simultâneos e relacionados, e essenciais da dinâmica da estrutura cognitiva, pois "toda aprendizagem que resultar em reconciliação integradora resultará também em maior diferenciação progressiva de conceitos ou proposições existentes" (MOREIRA, 2016, p. 34).

Para que a aprendizagem seja significativa é necessário, principalmente, que o aprendiz manifeste disposição para aprender significativamente. Ele deve adotar uma atitude que possibilite relacionar o que está sendo exposto de maneira não-arbitrária à sua estrutura cognitiva, ou seja, vincular o novo conhecimento ao que ele já sabe (MOREIRA, 2016). Mesmo que as condições anteriores sejam atendidas e o material pedagógico produzido pelo docente seja potencialmente significativo, o aluno pode escolher fixá-lo na memória de forma arbitrária e literal, tornando o processo de aprendizagem e o seu produto meramente mecânicos, ou seja, a pré-disposição de aprender do estudante é determinante para a aprendizagem significativa (MOREIRA et al., 2000).

A presença de subsunçores adequados nas estruturas cognitivas do indivíduo é condição fundamental para que a aprendizagem significativa aconteça. A clareza e a firmeza das ideias ancoradas determinarão o nível e a estabilidade do aprendizado. A disponibilidade desses subsunçores relevantes é condição fundamental para que a aprendizagem significativa aconteça (MOREIRA, 2012). A aprendizagem significativa necessita que o material de ensino seja potencialmente significativo para os aprendizes, portanto particularmente relacionado com a suas estruturas cognitivas (AUSUBEL, 2000).

Outro conceito fundante da teoria de Ausubel (2000) são os organizadores prévios, que são ferramentas pedagógicas que auxiliam no processamento dos princípios da diferenciação progressiva e da reconciliação integradora, pois criam pontes entre o que o aprendiz já sabe e o que precisa de saber (MOREIRA et al., 2000). Assim o papel desses organizadores, após a interação com os subsunçores relevantes na estrutura cognitiva, é prover suporte "ideário" para a agregação e retenção estável do material mais detalhado e diferenciado (AUSUBEL, 2000).

A aprendizagem significativa pode ser facilitada pela utilização de conteúdos introdutórios que tem como objetivo favorecer a assimilação das novas informações com os subsunçores adequados existentes. Esses materiais introdutórios possuem maior generalidade, abstração e inclusão que podem potencializar relacionamentos não-arbitrários e substantivos entre os novos conceitos e as ideias âncora presentes na estrutura cognitiva do aprendiz. (MOREIRA, 1999).

\section{Aprendizagem Baseada em Projetos}

De acordo com José Moran, a aprendizagem torna-se mais significativa quando os alunos são motivados e as práticas propostas lhes fazem sentido, envolvendo-os em projetos com diálogo sobre o que e como fazer, a fim de que resulte em contribuições. Nesse sentido, a adoção de metodologias de aprendizagem ativa são formas para desenvolver o conhecimento profundo nas habilidades socioemocionais e em novas práticas (MORAN, 2013).

A aprendizagem ativa precisa de ambientes próprios para as atividades do aluno. Esses locais comumente utilizam mapas conceituais, discussão de temas específicos, trabalho em equipe, estudo de caso, debates, geração de ideias (brainstorming) e atividades de investigação e pesquisa (DA SILVA, 2016). 
Essas metodologias destacam o aluno como personagem principal, em que o seu comprometimento, sua participação e reflexão são essenciais durante todas as etapas do seu processo de aprendizagem, onde ele experimenta. Propondo a mudança de papéis do aluno e do professor frente ao processo de aprendizagem, essas metodologias tornam o aluno protagonista e o professor um mediador. Dessa forma, aluno sai da condição de ouvinte e passa a participar e interagir mais no seu processo de aprendizagem (LEAL; MIRANDA; CASA NOVA, 2017).

Existe uma variedade de métodos que podem ser utilizados nas metodologias ativas. Entre esses métodos, destaca-se a aprendizagem baseada em projetos, que compreende uma metodologia ativa com a finalidade de envolver os alunos na aquisição de conhecimentos e competências utilizando projetos reais e efetivos. Os projetos devem possibilitar a investigação de problemas ou tarefas, que sejam motivadoras, dinâmicas e que permitam abordar temas acadêmicos para sua resolução, objetivando uma aprendizagem eficiente e eficaz (BENDER, 2014; JOCELEN et al, 2012).

No desenvolvimento dos projetos, existe a preocupação de gerar um produto. Assim, os alunos buscam atingir um objetivo compartilhado por meio da colaboração, ou seja, o enfoque é a construção coletiva do conhecimento interdisciplinar, por meio do protagonismo. Eles aprendem fazendo, em cooperação com os colegas. Dessa forma, os alunos precisam planejar as ações de sua equipe conforme avançam na solução do problema, criando um plano de ação e começando a conceber o esboço para o desenvolvimento de seus produtos (BACICH; MORAN, 2018).

Segundo o Buck Institute For Education (2008), para que um projeto seja efetivo, ele deve reconhecer o ímpeto para aprender intrinsecamente aos alunos, envolvendo-os nos conceitos e princípios centrais de uma disciplina, destacando questões provocativas. Deve também requerer a utilização de ferramentas e habilidades essenciais, incluindo tecnologia para aprendizagem, autogestão e gestão de projeto, além de especificar produtos que resolvam problemas, incluindo múltiplos produtos que permitam feedback. Precisa utilizar avaliações baseadas em desempenho e estimular alguma forma de cooperação.

Promover a aprendizagem significativa utilizando metodologias diferenciadas como a ABP é uma das maneiras de motivar os alunos a participarem e a desafiarem a si mesmos a fim de que as aulas não se tornem monótonas e pouco atrativas, mas sim motivadoras e incentivadoras na busca pelo conhecimento.

\section{O Ensino de Redes de Computadores}

A compreensão das diferentes formas de comunicação entre dois dispositivos eletrônicos é o ponto fundamental da disciplina de redes de computadores. A combinação entre hardware e software formam uma rede de computadores. São esses itens que efetuam o transporte dos sinais entre os enlaces e provêm os serviços disponíveis em uma rede, respectivamente (FOROUZAN, 2008).

Para diminuir a complexidade, as redes são estruturadas como uma pilha de camadas ou níveis sobrepostos. O objetivo de cada camada é proporcionar serviços às camadas superiores, sem que estas necessitem conhecer os detalhes da implementação destes serviços. (TANENBAUM; WETHERALL, 2011). Assim, foi desenvolvido pela ISO no final da década de 70, o modelo de Interconexão de Sistemas Abertos (Open System Interconnection - OSI), uma estrutura aberta formada por camadas para a padronização internacional dos protocolos com o objetivo de permitir a comunicação entre todos os tipos de sistemas independentemente 
de sua arquitetura (FOROUZAN, 2008). Ele é composto por sete camadas distintas, relacionadas entre si, que possuem funções bem definidas de cada parte do processo de comunicação através de uma rede.

Similarmente, o conjunto de protocolos TCP/IP (Transmition Control Protocol/Internet Protocol) teve seu desenvolvimento iniciado nos anos 70 apoiado pela DARPA (TANENBAUM; WETHERALL, 2011). Este modelo foi desenvolvido antes do OSI. Dessa forma, as camadas não correspondem exatamente entre si. No modelo de referência TCP/IP, como passou a ser conhecido, (TANENBAUM; WETHERALL, 2011), as pilhas de protocolos TCP/IP fornecem funcionalidades específicas, divididas em quatro camadas, mas que não são necessariamente interdependentes, pois podem ser mescladas e combinadas de acordo com a necessidade do sistema. Esse modelo tornou-se a arquitetura predominante, pois foi usado e testado intensamente na Internet. (FOROUZAN, 2008).

Várias estratégias pedagógicas são utilizadas para o ERC, tais como: (a) laboratórios virtuais (BELZARENA; GONZALEZ-BARBONE, 2008; FERREIRA et al, 2013; VOSS et al, 2013), esses trabalhos trazem como proposta para o ensino de redes a utilização de laboratórios virtuais que auxiliam na realização das atividades práticas da disciplina de redes de computadores permitindo melhores resultados no aprendizado e têm como diferencial o desenvolvimento das atividades de qualquer lugar que o aluno esteja; (b) uso de um ambiente em nuvem para o ERC através do simulador Netkit, possibilitando a realização das práticas de rede em ambiente de nuvem de computadores (SANTOS, 2017); (c) jogos sérios para o ensino de redes de computadores (HERPICH, 2013; KRASSMANN, 2016; VOSS; NUNES; MEDINA, 2013) e uso de jogos concretos e desplugados (MELGAÇO; DIAS, 2019) - o propósito dos jogos é complementar o processo de ensino e aprendizagem dos estudantes através do desenvolvimento de atividades como simulações e resolução de problemas; (d) uso de agentes pedagógicos (FREITAS, 2017) e agentes inteligentes (HERPICH, 2015) em um mundo virtual que tem como foco o ensino de conceitos de redes de computadores.

Existem outros trabalhos relacionados ao ensino de redes de computadores, porém apenas alguns foram selecionados para compor o corpo deste artigo, pois o objetivo era conhecer as soluções propostas para os problemas enfrentados no processo de ensino e aprendizagem e identificar as principais estratégias adotadas, considerando se usaram recursos virtuais ou se concentravam-se em dispositivos físicos.

Após alguns estudos, percebeu-se que o ERC com robótica educacional seria uma alternativa, uma vez que usando Arduino e o módulo ESP8266 01 seria possível abordar os modelos OSI e TCP/IP (camadas física, enlace, redes/Internet, transporte e aplicação). Além de explorar a comunicação com e sem fio, endereços físicos e lógicos, encaminhamentos, sockets e o uso de protocolos como Hypertext Transfer Protocol (HTTP), Domain Name System (DNS) e Dynamic Host Configuration Protocol (DHCP). Usando a RE foi possível aplicar de modo prático como ocorre a comunicação entre os diferentes tipos de equipamentos, e como esses modelos são usados.

\section{Percurso Metodológico}

Para o desenvolvimento da experiência de aprendizagem relatada neste trabalho, foram realizadas, inicialmente, a pesquisa bibliográfica e a pesquisa documental. A pesquisa bibliográfica possibilitou estabelecer a abordagem pedagógica que integra $\mathrm{ABP}$ e a teoria da aprendizagem significativa, assim como identificar os conteúdos de redes mais trabalhados nos 
cursos de informática do IFRS. Através dessa pesquisa foram identificados alguns dos trabalhos aplicado ao ERC, os quais foram descritos previamente.

A pesquisa documental compreendeu uma análise detalhada das matrizes curriculares e dos planos de ensino dos componentes curriculares vinculados a redes de computadores, no contexto dos 17 campi do IFRS. Isso foi necessário porque conteúdos iguais podem ser abordados usando nomenclaturas diferentes. Além disso, foi possível mapear os conteúdos trabalhados e generalizá-los sob um conceito comum. Por exemplo, "Endereçamento IP: conceito de máscara de sub rede, classes, roteamento e gateway", foi mapeado como serviços da camada de rede. A Figura 1 esquematiza os conceitos identificados nesta pesquisa documental realizada e os organiza usando um mapa conceitual.

Figura 1 - Mapa Conceitual das Disciplinas de Redes I e II

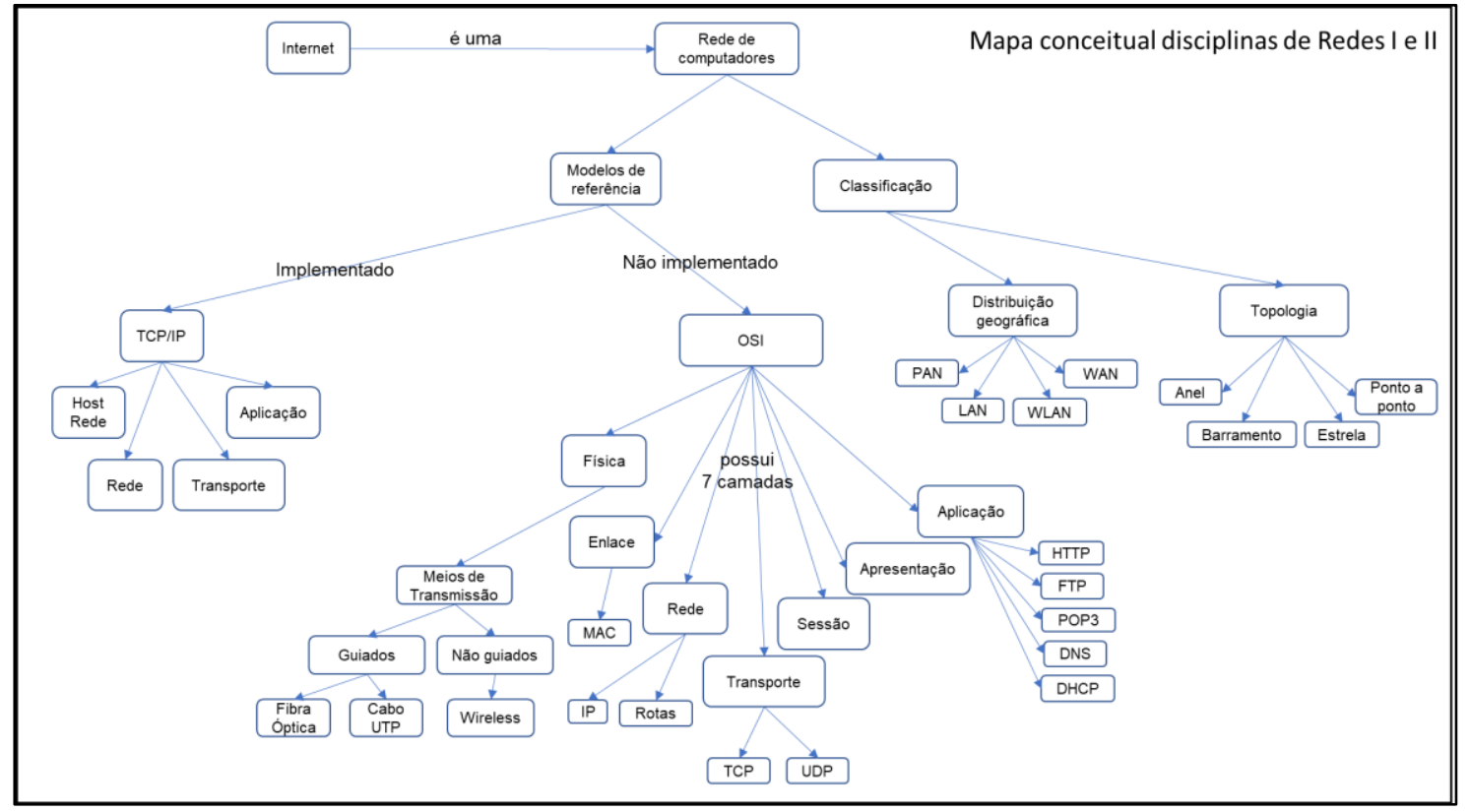

Fonte: Elaborada pelos autores (2019)

A pesquisa-ação foi selecionada para conduzir o trabalho, pois como argumentam Filippo, Roque e Pedrosa (2019, p. 17), cabe ao pesquisador "selecionar ou projetar ações apropriadas para aquele contexto específico com o objetivo de, por exemplo, contribuir para a melhoria da aprendizagem e promover o aumento do interesse, da autonomia e da cooperação dos alunos". Conforme já mencionado, essa atividade foi realizada com 14 estudantes do curso Técnico de Informática Subsequente ao Ensino Médio, do IFRS - campus Veranópolis, que consentiram com a participação no projeto de pesquisa.

Antes de começar a pesquisa propriamente dita, na primeira aula do semestre foi aplicado um questionário (chamado de pré-teste), que continha perguntas sobre os conteúdos previamente estudados, de modo a identificar quais seriam os subsunçores (conhecimentos prévios) que os estudantes teriam disponíveis ao iniciar a disciplina. Esse teste contemplou perguntas contendo os conhecimentos básicos que seriam necessários para o desenvolvimento do projeto. A Figura 2 ilustra algumas das questões que integraram o pré-teste aplicado com os participantes da pesquisa. 
Figura 2 - Pré-teste aplicado com os participantes da pesquisa (parcial)

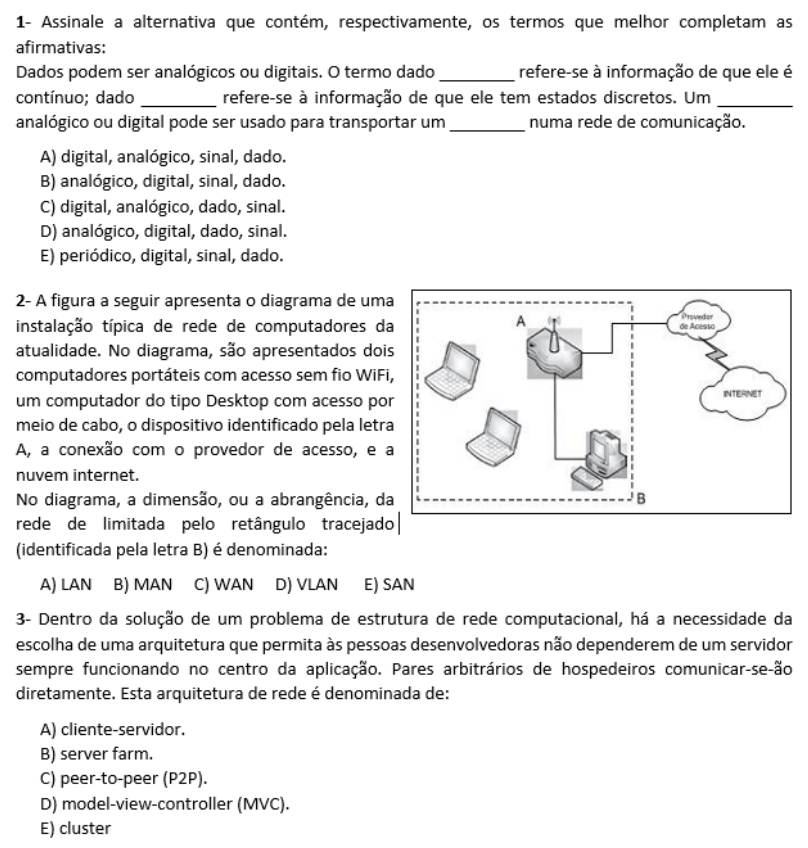

Fonte: Elaborada pelos autores (2019)

Com base na análise dos resultados do pré-teste, foi possível verificar o nível de conhecimento inicial dos indivíduos. As informações serviram de entrada para o planejamento das aulas subsequentes. Além disso, foi realizada a sistematização dos componentes eletrônicos e dos recursos vinculados à robótica educacional que seriam usados e desenvolvidos, bem como eles poderiam se correlacionar com os conteúdos de redes de computadores. Também foram definidos materiais introdutórios para facilitar a aprendizagem significativa e desenvolver a reconciliação integrativa. O Quadro 1 esquematiza o planejamento de uma das aulas aplicadas com os participantes da pesquisa. As colunas correspondem ao planejamento de cada aula: (i) a primeira define o conteúdo da área de redes de computadores que será abordado para aquela aula; (ii) a segunda estabelece objetivos de aprendizagem esperados; (iii) a terceira realiza um mapeamento dos passos que serão desenvolvidos durante a aula; (iv) a avaliação é a coluna destinada a especificar quais são os instrumentos de avaliação que serão usados; (v) a quinta coluna define quais os recursos didáticos para a condução da aula; e, por fim, (vi) a bibliografia básica usada no planejamento da aula, e de seus materiais pedagógicos, é explicitada.

Quadro 1 - Planejamento realizado para a Aula 3

\begin{tabular}{|c|c|c|c|c|c|c|}
\hline & CONTEÚDO & OBJETIVOS & DESENVOLVIMENTO & AVALIAÇÃO & $\begin{array}{l}\text { RECURSOS } \\
\text { DIDÁTICOS }\end{array}$ & $\begin{array}{l}\text { BIBLIOGRÁFIA } \\
\text { BÁSICA }\end{array}$ \\
\hline 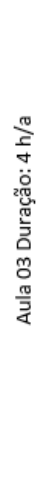 & $\begin{array}{l}\text { Comunicação } \\
\text { sem fio } \\
\text { Conceitos de } \\
\text { redes de } \\
\text { computadores } \\
\text { Pilha de } \\
\text { protocolos do } \\
\text { Modelo OSI e } \\
\text { TCP/IP }\end{array}$ & $\begin{array}{l}\text { Entender o } \\
\text { funcionamento e } \\
\text { utilizações do ESP8266 } \\
01 \\
\text { Realizar a ligação do } \\
\text { componente }\end{array}$ & $\begin{array}{l}\text { Apresentar o módulo ESP8266 } \\
01 \text { e como este pode ser } \\
\text { utilizado e qual sua função no } \\
\text { projeto } \\
\text { Explicar os conceitos de redes } \\
\text { de computadores utilizados } \\
\text { na comunicação do Arduino } \\
\text { com a infraestrutura de rede } \\
\text { montada } \\
\text { Situar a sua implementação } \\
\text { sob a pilha de protocolos do } \\
\text { Modelo OSI e TCP/IP, } \\
\text { - Realizar a ligação do } \\
\text { módulo } \\
\text { - Testar a comunicação com } \\
\text { a rede. }\end{array}$ & $\begin{array}{l}\text { Verificar por meio de } \\
\text { observação: } \\
\text { - O processo de montagem } \\
\text { - A aderência as atividades } \\
\text { propostas } \\
\text { - As estruturas montadas. }\end{array}$ & $\begin{array}{l}\text { Projetor } \\
\text { Microcontrolador } \\
\text { Arduino } \\
\text { Módulo } \\
\text { ESP8266 ESP01 } \\
\text { Roteador WiFi } \\
\text { Servidor Linux } \\
\text { Switch } \\
\text { Componentes } \\
\text { eletrônicos } \\
\text { diversos }\end{array}$ & $\begin{array}{l}\text { IGOE, T. Making } \\
\text { Things Talk. 2. ed. } \\
\text { O'Reilly, 2011. } \\
\text { Capítulos 2, } 3 \text { e } 6 \\
\text { SCHWARTZ, M. } \\
\text { Internet of Things } \\
\text { with ESP8266. } \\
\text { Birmingham: Packt } \\
\text { Publishing, 2016. } \\
\text { Capítulos 1,2,4,5 } \\
\text { JAVED, A. Building } \\
\text { Arduino Projects for } \\
\text { the Internet of } \\
\text { Things. New York: } \\
\text { Apress. 2016. } \\
\text { Capítulos 1,2,3 }\end{array}$ \\
\hline
\end{tabular}

Fonte: Elaborada pelos autores (2019) 
Para verificar o quanto o aluno conseguiu assimilar dos conteúdos de redes de computadores usando ABP e RE, foi aplicado um teste final com perguntas que abordaram os mesmos assuntos do teste inicial, só que usando uma outra representação visual. Esse teste final (Figura 3) teve o propósito de determinar o grau em que os objetivos educacionais relevantes foram alcançados. Nesse teste, cada pergunta possuía uma correlação teórica com as perguntas do pré-teste, pois só assim seria possível identificar se houve ou não evolução do conhecimento de cada participante. Cabe destacar que o teste final foi aplicado na última aula em que a pesquisa-ação foi conduzida.

Figura 3 - Teste final aplicado com os participantes da pesquisa (parcial)

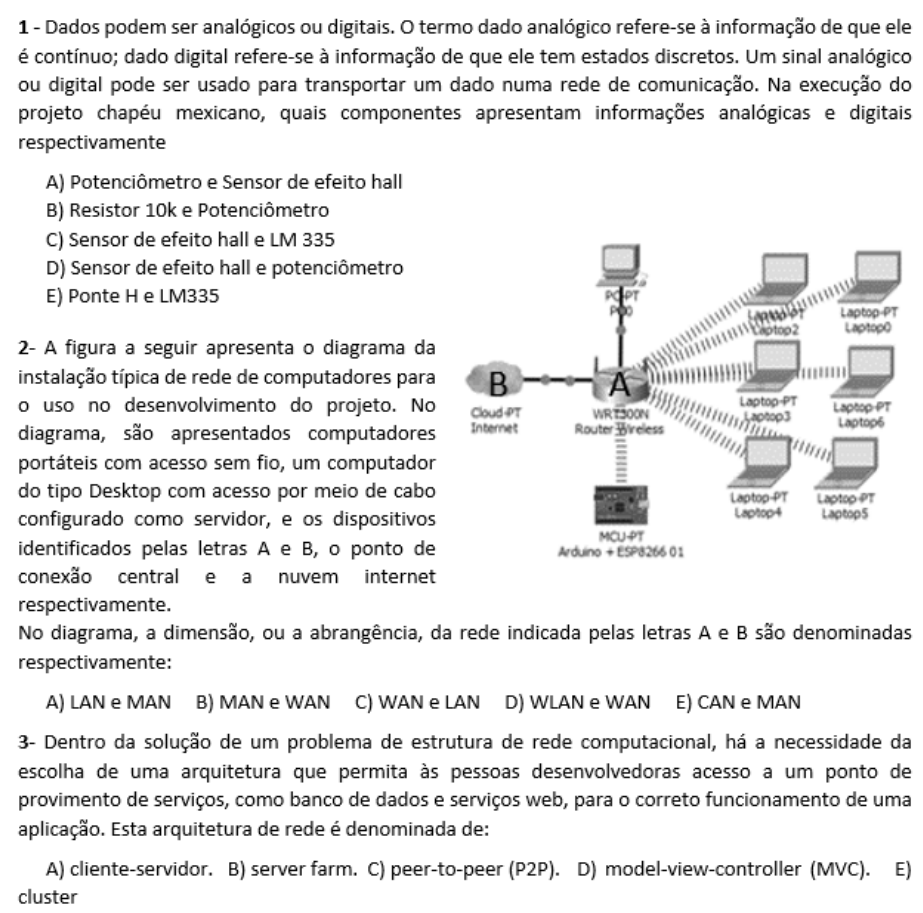

Fonte: Elaborada pelos autores (2019)

Por fim, foi aplicado um questionário avaliativo da atividade com perguntas abertas e fechadas e com o propósito de identificar aspectos que deveriam ser aprimorados na experiência de aprendizagem. O método escolhido para a análise dos dados coletados, a partir da aplicação dos testes, foi o de Análise de Conteúdo Temática, técnica de tratamento de dados coletados que busca a interpretação de material qualitativo, proporcionando uma descrição objetiva, sistemática e com a riqueza manifesta no momento da coleta dos mesmos. Esse método se dá em três etapas: pré-análise, exploração do material e tratamento dos resultados (GUERRA, 2014).

Para a pré-análise, foram utilizados como entrada de dados os resultados obtidos com o pré-teste e teste final respondidos pelos alunos. Nessa etapa da pesquisa, eles foram organizados com o objetivo de torná-los operacionais e assim sistematizar as ideias iniciais para que fosse seguida uma estratégia precisa para o desenvolvimento das atividades do plano de análise (BARDIN, 2016). Dessa forma, os testes coletados foram organizados para a realização do cruzamento dos dados e assim fossem levantadas as informações que seriam consideradas.

$\mathrm{Na}$ segunda etapa, com a exploração do material, foi realizada a codificação desse material com a finalidade de que os dados brutos atingissem a representação do conteúdo para que pudessem ser categorizados e, então, utilizados como entrada para o processo de enumeração (BARDIN, 2016). O tratamento desse material consistiu em transformar os dados, 
de acordo com regras precisas, em informação significativa e válida que permitisse inferências e interpretações acerca dos objetivos propostos. No processo de codificação dos dados foi realizada a seleção de unidades de registro, isto é, o delineamento que se deu na pesquisa. Essa unidade de registro pode ser uma frase, um tema ou uma palavra (SANTOS, 2012). Na etapa de enumeração, foram estabelecidas as regras de contagem. Assim, pode-se verificar a existência ou a ausência de determinadas unidades de registros que foram relevantes para a pesquisa. Outro aspecto importante do processo de enumeração é a frequência observada de uma unidade de registro e sua a intensidade medida através da direção favorável, neutra ou desfavorável e demais critérios associados (positivo ou negativo) (SANTOS, 2012).

\section{Prática Pedagógica: etapas e recursos utilizados}

O desenvolvimento de um projeto envolve os estudantes em uma sequência complexa de tarefas que demandam planejamento e organização, de modo que se tenha como resultado uma solução para o problema. Para isso, é fundamental dividir responsabilidades e tomar decisões cooperativamente (BENDER, 2014). Com a utilização dessa metodologia ativa, procura-se estruturar, motivar e enriquecer a estratégia pedagógica e o processo criativo com a finalidade de que os estudantes tentem atingir melhores resultados no seu aprendizado.

Para a introdução de um projeto, é preciso estabelecer uma âncora que servirá para apoiar o ensino baseado em uma situação do mundo real (BENDER, 2014). Para tanto, foi definido, em conjunto com outros docentes do campus, que o projeto seria um dispositivo que viabilizasse o ensino de conceitos de física, especificamente do Movimento Circular Uniforme (MCU). Partindo-se desse contexto, ficou definido como a âncora do projeto o MCU. Em seguida, iniciou-se o processo de busca por soluções e formas de atender aos requisitos. Após algumas investigações, resolveu-se criar um objeto que possuísse analogia com a vida real, sendo que foi selecionada a temática de brinquedos de parques de diversões.

Assim, ao pesquisar exemplos, deparou-se com o brinquedo Chapéu Mexicano, comum em parques de diversão, o qual é formado por balanços pendurados em uma estrutura apoiada em um disco circular e sustentado por um cilindro. Seu movimento ocorre por meio de um motor elétrico que faz a estrutura girar e assim os balanços se abrem, e as forças centrípeta e centrifuga, que mantém o movimento circular, acabam elevando-os e formando uma estrutura semelhante a um chapéu. O produto a ser desenvolvido no contexto do projeto deveria ser capaz de efetuar medições dos parâmetros de velocidade linear e angular, frequência, período e aceleração centrípeta, e de enviar todas as medições realizada para um banco de dados, as quais são lidas e calculadas e, posteriormente exibidas em uma página web. Outra funcionalidade esperada é a geração de gráficos que deveriam exibir a variação dos fenômenos capturados. Com esses requisitos, é possível que docentes de física forneçam aos alunos exemplos visuais da ocorrência desse movimento, realizar experimentações sobre esses fenômenos, como a variação da velocidade linear e suas consequências, bem como demonstrar em tempo real os gráficos de variação desse movimento.

A questão motriz que norteou o desenvolvimento do projeto foi: de que forma um dispositivo robótico poderia demonstrar os fenômenos do MCU? Para isso, os alunos precisaram identificar quais são as características e fenômenos que compõe o movimento circular uniforme e de que forma poderia ser desenvolvida uma solução que possibilitasse demonstrar as características e experimentações sobre esses fenômenos.

Para o desenvolvimento das atividades, os alunos foram divididos em grupos de três alunos e cada integrante com papéis e responsabilidades importantes: (i) o líder, responsável 
pela coordenação, documentação e suporte ao grupo; (ii) o engenheiro, responsável pelo desenvolvimento da solução para o problema proposto; e (iii) o programador, que codifica os itens necessários para a solução. Para acompanhar o desenvolvimento do trabalho em equipe foi selecionado o método Kanban e a ferramenta Trello (disponível em: https://trello.com/pt$\mathrm{BR}$ ), onde cada grupo criou um quadro e compartilhou com o professor para o acompanhamento da realização das atividades.

Para elaborar o produto final, os alunos utilizaram o módulo ESP8266 01 por ser o mais conhecido, de tamanho reduzido e de baixo custo (SCHWARTZ, 2016). O chip ESP8266 proporciona uma solução completa e independente de rede $W i-F i$ - opera nos padrões 802.11 b/g/n - e possui a pilha de protocolos TCP/IP integrada. Este módulo ao ser utilizado como adaptador $\mathrm{Wi}-\mathrm{Fi}$ pode interligar projetos baseados em microcontroladores com comunicação simples, como o Arduino, à Internet. Desta forma, com a utilização do ESP8266 01, percebeuse que foi possível atingir os objetivos propostos no projeto. Com esse componente eletrônico, foi possível abordar os conteúdos de redes de computadores descritos previamente. De modo a sintetizar visualmente os conteúdos explorados (cor verde), foi elaborada a Figura 4, que compreende um mapa conceitual.

Figura 4 - Mapa Conceitual dos Conteúdos Abordados com o ESP8266-01

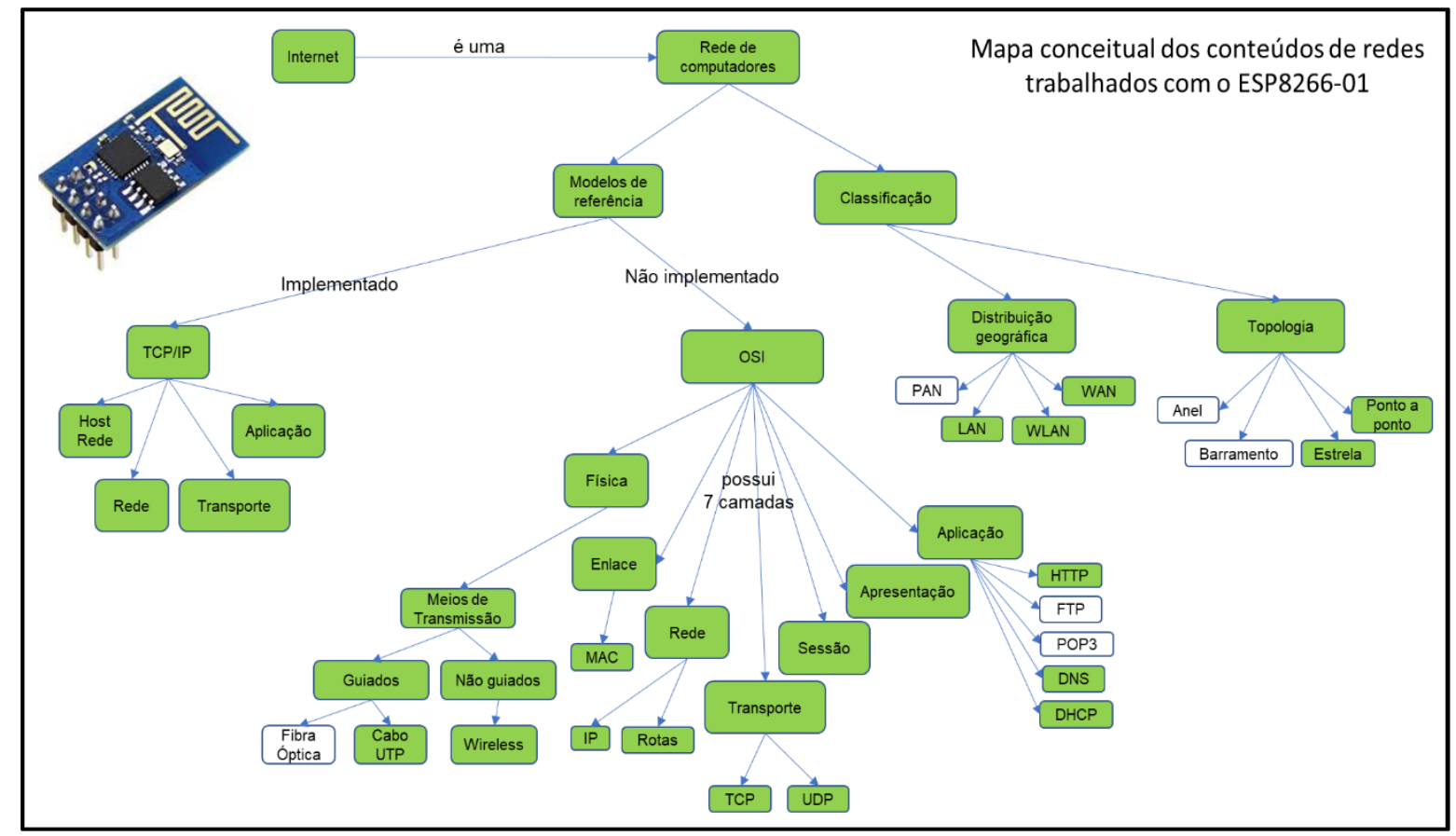

Fonte: Elaborada pelos autores (2019)

Para o desenvolvimento do projeto, alguns conceitos vinculados à teoria da aprendizagem significativa, bem como alguns passos definidos pela ABP, foram adotados. $\mathrm{O}$ primeiro consiste em delimitar o problema a que se quer resolver, em seguida é necessário definir quais as unidades e objetivos de aprendizagem. Com base nessas informações é preciso estabelecer uma âncora para o projeto, que vai fundamentar o ensino em um cenário do mundo real, a partir da âncora é necessário pensar na questão motriz que vai fornecer a tarefa geral ou a meta para o projeto. Na sequência as tarefas que devem ser realizadas para se obter a solução necessitam ser estabelecidas, desde a divisão de responsabilidades passando pela tomada de decisão coletiva, até o desenvolvimento do produto. Outro ponto que precisa ser planejado são os materiais que serão utilizados e as ferramentas necessárias para o desenvolvimento do 
projeto. Por fim, na etapa de planejamento, deve-se elencar os itens previstos como possíveis soluções para o projeto, estabelecendo quais produtos deverão ser gerados pelo aluno.

O Quadro 2 apresenta uma síntese das etapas da experiência de aprendizagem que foi conduzida. É possível perceber que a teoria da aprendizagem significativa foi aplicada em todas as fases previstas. Observa-se ainda que os aspectos teóricos vinculados à $\mathrm{ABP}$ devem ser empregados durante o planejamento e o desenvolvimento das aulas.

Quadro 2 - Etapas para Aplicação da ABP e da Teoria da Aprendizagem Significativa

\begin{tabular}{|c|c|c|c|}
\hline \multicolumn{1}{|c|}{ Pré-teste } & Planejamento das aulas & Desenvolvimento das aulas & \multicolumn{1}{c|}{ Teste Final } \\
\hline AUSUBEL & \multicolumn{1}{|c|}{$\begin{array}{c}\text { AUSUBEL } \\
\text { ABP }\end{array}$} & \multicolumn{1}{c|}{$\begin{array}{c}\text { AUSUBEL } \\
\text { ABP }\end{array}$} & AUSUBEL \\
\hline $\begin{array}{l}\text { Saber o que o aluno } \\
\text { já sabe sobre a } \\
\text { unidade de } \\
\text { aprendizagem a ser } \\
\text { abordada no projeto. }\end{array}$ & $\begin{array}{l}\text { Planejar as unidades e os objetivos } \\
\text { de aprendizagem } \\
\text { introdutón os materiais } \\
\text { Definir: } \\
-\quad \begin{array}{l}\text { Materiais a serem } \\
\text { utilizados } \\
\text { Avaliação } \\
\text { Recursos didático } \\
\text { Bibliografia básica }\end{array}\end{array}$ & $\begin{array}{l}\text { Utilizar da diferenciação } \\
\text { progressiva, para que seja } \\
\text { facilitada as ligações entre } \\
\text { os conteúdos. }\end{array}$ & $\begin{array}{l}\text { Perguntas apresentadas pelo } \\
\text { teste do pós-teste tem } \\
\text { relação com os conteúdos } \\
\text { abordados no pré-teste. } \\
\text { Isso permitirá identificar se } \\
\text { houve ou não evolução no } \\
\text { desempenho do aluno, em } \\
\text { cada um dos tópicos } \\
\text { explorados. }\end{array}$ \\
\hline
\end{tabular}

Fonte: Elaborado pelos autores (2019)

Com base nessas teorias, pode-se perceber o quanto o planejamento didático é importante para usar recursos tecnológicos em sala de aula. O planejamento guiou a escolha dos materiais e recursos didáticos usados, os procedimentos de avaliação, a bibliografia e o desenvolvimento das aulas.

Por fim, é importante mencionar que, em um primeiro momento, como os alunos não haviam trabalhado com robótica educacional previamente, os novos conhecimentos foram apresentados de maneira mecânica, pois o aluno dificilmente conseguiria fazer a relação com conhecimentos prévios, visto que esse era um assunto novo e não trabalhado anteriormente. Assim, após um momento de aprendizagem mecânica, a aprendizagem passou a ser significativa. Para isso, foram criados organizadores prévios no formato de materiais introdutórios, apresentando o novo conhecimento e seu relacionamento com os subsunçores existente na estrutura cognitiva do aluno para criar a associação dos conceitos da robótica educacional com os sistemas computacionais.

Seguindo o que estabelece a teoria de Ausubel (2000), em cada aula um conceito era apresentado e, posteriormente, era gradativamente particularizado, ou seja, de uma aula para outra as diferenças, semelhanças e distinções relativas ao conteúdo eram exploradas em aulas expositivas e dialogadas com os estudantes. Desse modo, a diferenciação progressiva era incentivada e a reconciliação integrativa ocorria de forma natural.

\section{Discussões e resultados}

Conforme mencionado previamente, os alunos responderam a um instrumento avaliativo chamado de pré-teste e um outro denominado de teste final. Esses testes serviram para verificar se houve ou não evolução dos estudantes durante o processo de aprendizagem, 
visto que é necessário verificar se um novo conhecimento é ou não ancorado nos conhecimentos prévios. Assim, o Gráfico 1 demonstra que ocorreu um aumento no número de acertos no teste final em relação ao teste inicial. De acordo com HERPICH et al. $(2013$, p. 2) "o ensino e aprendizagem de redes de computadores não é uma tarefa fácil, embora seja possível ensinar e aprender por meio de livros, conceitos e teorias, como normalmente a disciplina de redes de computadores é apresentada, a prática é um fator de grande relevância no processo educacional". O ensino de redes de computadores é prejudicado se os conceitos não são bem esclarecidos, tornando-se tedioso e cansativo quando a abordagem pedagógica se restringe a exposição dialogada. Nesse sentido, o uso de estratégias de aprendizagem ativas, suportadas por teorias da aprendizagem podem beneficiar o processo de aquisição do conhecimento.

Assim, acredita-se que as atividades desenvolvidas com a adoção dessa prática pedagógica podem ser as responsáveis por esse aumento, pois quando o estudante consegue realizar ligações entre a teoria e a prática dos conteúdos estudados a produtividade do processo de aprendizagem é maior. A média de acertos no pré-teste foi de $51,33 \%$, já no teste final foi de $82,66 \%$. Ao comparar esses resultados é possível perceber que a média de acertos aumentou $31,33 \%$, exceto para um dos alunos que acabou desistindo da disciplina (ele é identificado como Aluno 8 no Gráfico 1).

Gráfico 1 - Número de acertos Pré-teste x Teste final por Participante

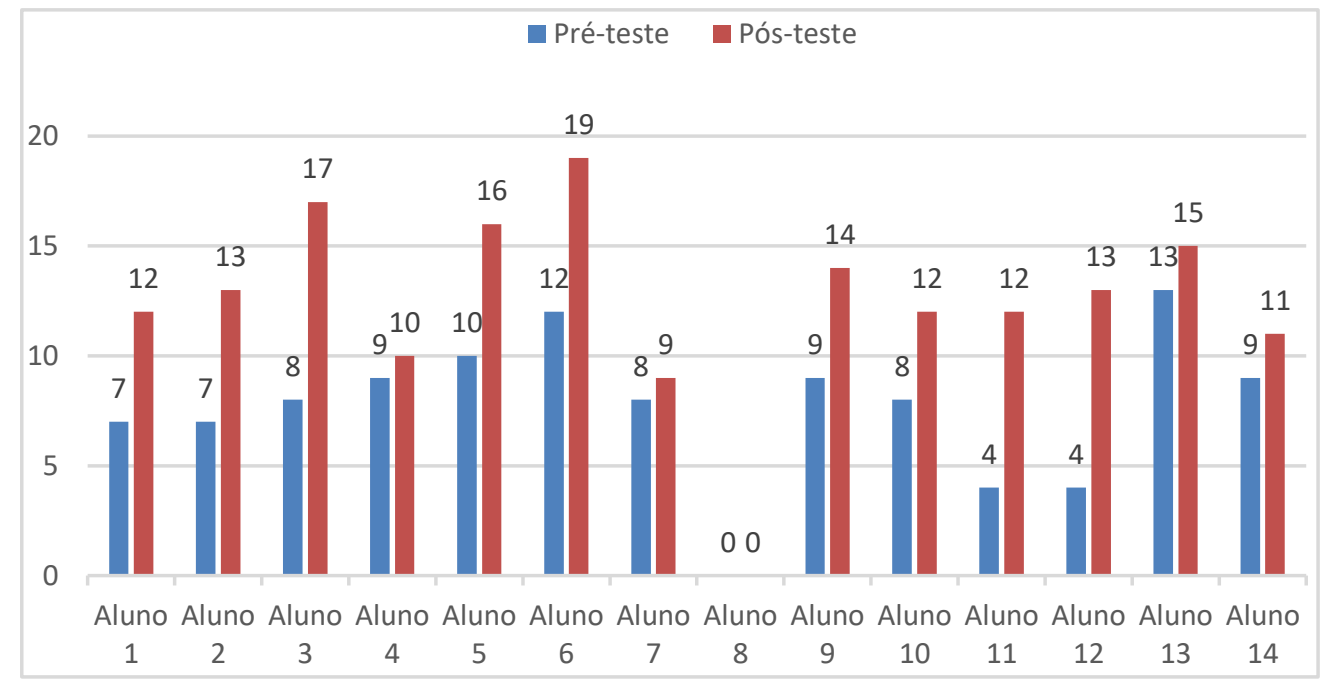

Fonte: Elaborado pelos autores (2019)

Outra análise realizada diz respeito aos assuntos de redes de computadores abordados nos dois testes. Pode-se concluir que os conteúdos que estão presentes no cotidiano do aluno, como classificação, dispositivos e arquiteturas de rede, não foram tão beneficiados pela experiência de aprendizagem, como os conceitos que possuem uma abordagem predominantemente teórica, como os modelos de redes. O Gráfico 2 esquematiza a variação de acertos dos estudantes por conteúdo abordado durante a prática pedagógica. 


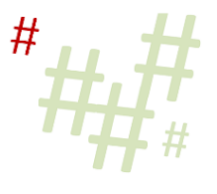

Gráfico 2 - Variação de acertos Pré-teste x Teste Final - Por conteúdo

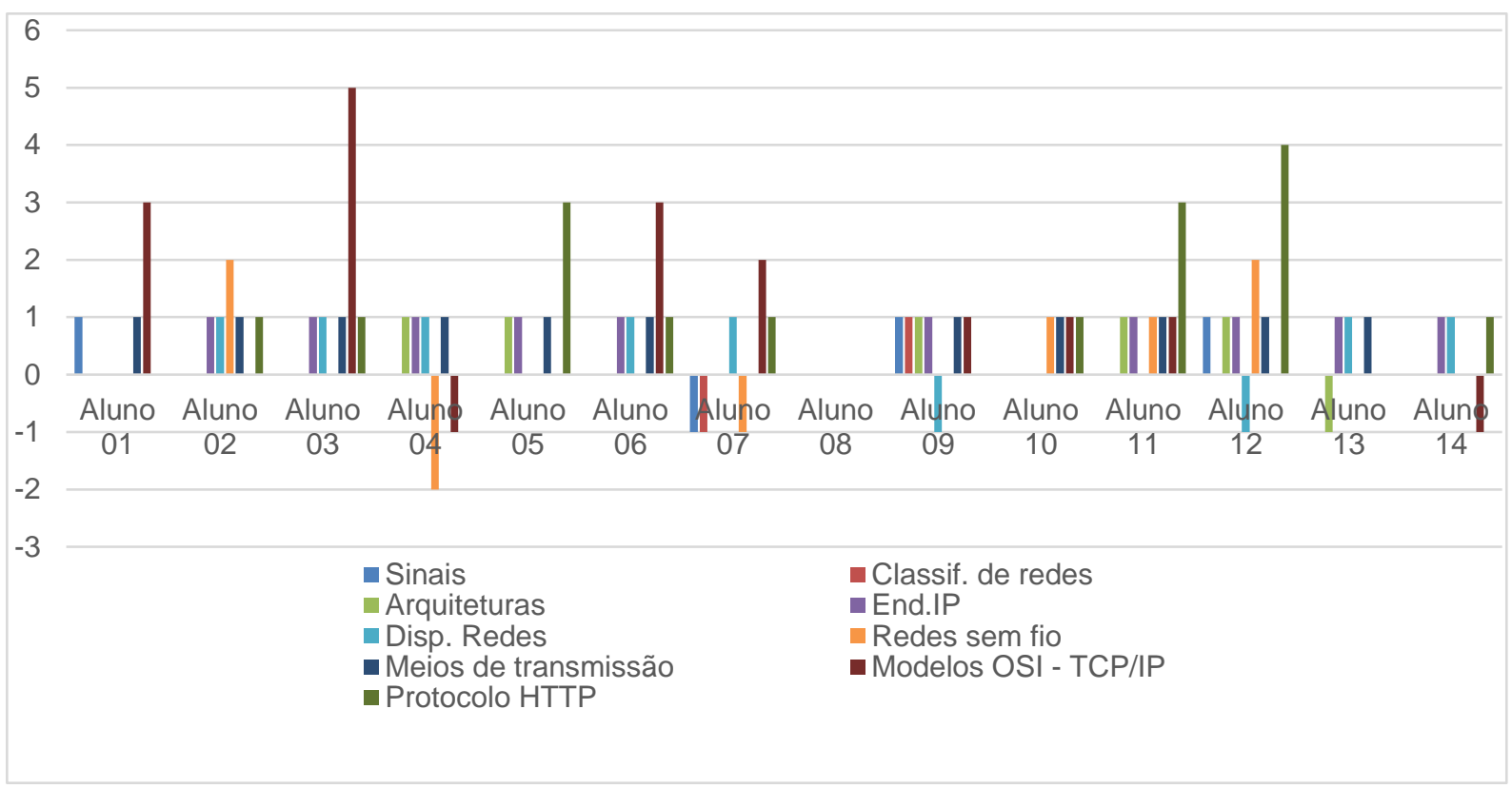

Fonte: Elaborado pelos autores (2019)

Outra avaliação que foi conduzida é a das percepções dos estudantes sobre a experiência de aprendizagem conduzida. Quando questionados sobre a troca de conhecimentos com os pares, 78,6\% dos estudantes disseram que a participação nessa pesquisa contribuiu para ampliar o compartilhamento do conhecimento. Quando indagados sobre o desenvolvimento do raciocínio lógico, 78,6\% afirmaram que a experiência de aprendizagem conduzida oportunizou estabelecer ligações com os saberes científicos e matemáticos e aprimorou a sua capacidade de resolução de problemas. Com relação ao protagonismo, 42,8\% acreditam que a pesquisa favoreceu a autonomia dos estudantes. E, considerando o engajamento, 71,4\% dos estudantes apontaram que esse tipo de atividade favorece muito o desenvolvimento dessa habilidade. Isso corrobora a teoria da aprendizagem significativa de Ausubel (2000), que estabelece que para o aluno aprender ele deve estar pré-disposto ou engajado em seu processo de aprendizagem.

Outro ponto que foi avaliado diz respeito ao grau em que as atividades desenvolvidas favoreceram as habilidades necessárias para a "sociedade da criatividade", em que é fundamental que os alunos tenham a capacidade de adaptação e improvisação frente a situações inesperadas que precisem responder. Afinal, segundo Resnick (2007, p. 18), para obter sucesso na sociedade da criatividade, o aluno precisa "aprender a pensar de forma criativa, planejar sistematicamente, analisar criticamente, trabalhar em colaboração, comunicar-se claramente, projetar iterativamente e aprender continuamente". Assim, com relação ao desenvolvimento da criatividade, 93,8\% dos estudantes participantes destacaram que a pesquisa conduzida favoreceu em algum grau a criatividade para resolver o projeto proposto.

Ao serem questionados sobre as dificuldades encontradas na execução do projeto, os estudantes apontaram como ponto mais complexo questões vinculadas à programação do sistema (42\%); em segundo lugar os conceitos vinculados com a parte eletrônica (29\%); e em terceiro a gestão do projeto (14\%), sendo que as dificuldades vinculadas à redes de computadores apareceram junto a outras questões. Essa dificuldade com as tarefas de programação prejudicou a interdisciplinaridade do trabalho, pois, ainda que básicas, era fundamental para a solução a ser desenvolvida. 
Sob a perspectiva do professor, a passividade dos alunos mostrou-se com um fator limitador, pois as atividades e os colegas ficavam prejudicados quando um indivíduo não buscava a solução para resolver os problemas vinculados ao projeto e ficava aguardando para replicar a solução dada pelo professor. A adoção de atividades práticas, nesse caso utilizando a robótica educacional, favoreceu o processo de aprendizagem, pois permitiu demonstrar aplicações práticas dos conceitos teóricos, bem como experimentações pelos alunos, que se motivaram para o desenvolvimento das atividades.

\section{Conclusões}

A adoção de elementos da teoria da aprendizagem significativa possibilitou planejar e estruturar melhor as aulas que foram ministradas. Uma vez que com o uso do pré-teste, da diferenciação progressiva, da reconciliação integrativa e dos organizadores prévios foi possível sistematizar cada conteúdo de modo a interligar os conceitos com atividades práticas. Com base no depoimento dos estudantes, é possível afirmar que a aplicação desses conceitos no desenvolvimento de atividades práticas, relacionadas com a atuação profissional, foram fundamentais para melhorar o processo de aprendizagem.

A ABP, além de auxiliar no planejamento das aulas, contribuiu para que os alunos percebessem de forma clara qual era o "produto" que deveriam desenvolver. A participação dos alunos na formulação do projeto, que deveria ser resolvido, incentivou o protagonismo e o engajamento nas atividades que foram propostas. A correlação do projeto com necessidades da comunidade foi outro fator determinante para a adesão dos estudantes à pesquisa. Eles compreenderam a importância de criar um produto funcional que seria usado por outros estudantes do ensino médio da própria escola, e com isso procuravam aprimorar suas soluções. O uso de um laboratório específico para o desenvolvimento da experiência também incentivou os estudantes, pois tinham espaços "privados" para deixar seus projetos entre uma aula e outra, incentivando nos estudantes a relação de pertencimento.

Como argumenta Ausubel (2020), para que a aprendizagem significativa ocorra é necessário que o aprendiz manifeste disposição para aprender significativamente; da mesma forma que Bacich e Moran (2018) descrevem que o uso de metodologias ativas passa pela autonomia e protagonismo do aluno, só que para isso ele deve estar disposto a aprender dessa forma. Assim, o aspecto a ser vencido para o uso desse tipo de experiência de aprendizagem é a dificuldade em romper a passividade que alguns alunos possuem; ao encontrarem uma dificuldade, não buscam a solução, ficam estagnados aguardando a resolução por parte do professor, já que essa forma é mais comum ao seu cotidiano escolar, replicar a solução dada pelo educador.

De qualquer forma, o trabalho permitiu identificar claramente a relação direta entre ABP e aprendizagem significativa e demonstrou que, na medida em que for planejada, essa relação pode conduzir a resultados de aprendizagem comprováveis, mais especificamente, no ensino de redes de computadores.

\section{Referências}

AUSUBEL, D. P. Aquisição e Retenção de Conhecimentos: uma perspectiva cognitiva. Lisboa: Platano, 2000.

BACICH, L.; MORAN, J. Metodologias Ativas para uma Educação Inovadora: uma abordagem teórico-prática. Porto Alegre: Penso, 2018. 
BARDIN, L. Análise de Conteúdo. São Paulo: 70, 2016.

BELZARENA, P.; GONZALEZ-BARBONE, V. Incorporacion de un Simulador Gráfico de Redes en un Objeto de Aprendizaje Reutilizablee-Spacio. Montevideo: UNED, 2006.

BENDER, N. W. Aprendizagem Baseada em Projetos: educação diferenciada para o século XXI. Porto Alegre: Penso, 2014.

BUCK INSTITUTE FOR EDUCATION. Aprendizagem Baseada em Projetos: guia para professores do ensino fundamental e médio. Porto Alegre: Artmed, 2008.

CAMPOS, F. R. Robótica Educacional no Brasil: questões em aberto, desafios e perspectivas futuras. RIAEE: Revista Ibero-Americana de Estudos em Educação, Araraquara, v. 12, n. 4, p. 2108-2121, 2017.

COLL, C.; MONEREO, C. Educação e Aprendizagem no Século XXI: novas ferramentas, novos cenários, novas finalidades. In: COLL, C.; MONEREO, C. (org.). Psicologia da Educação Virtual: aprender e ensinar com as tecnologias da informação e comunicação. Porto Alegre: Artmed, 2010. p. 15-46.

CORINO, M. J. V. ROBORA: encorajando o uso da robótica educativa no ensino técnico e tecnológico de informática. 2019. Dissertação (Mestrado) - Mestrado Profissional em Informática na Educação do Instituto Federal de Educação, Ciência e Tecnologia do Rio Grande do Sul (MPIE/IFRS), Porto Alegre, 2019.

COSTA JUNIOR, A. O. Uma estratégia utilizando robótica para o ensino dos conceitos de velocidade e aceleração escalares. 2017. Dissertação (Mestrado) - Mestrado Profissional em Ensino Tecnológico, Instituto Federal de Educação, Ciência e Tecnologia do Amazonas (IFAM), Manaus, 2017.

DA SILVA, W. Metodologias ativas de aprendizagem: relato de experiência com aprendizagem baseada em projetos. [s.l: s.n.]. Disponível em:

https://www.isesion.edu.br/artigos/05-prendizagem_baseada_projetos-sion.pdf. Acesso em: 19 nov. 2018.

FERREIRA, K. H. A. et al. Laboratório Virtual para o Ensino de Redes de Computadores no Moodle. In: Simpósio Brasileiro de Informática na Educação, 24, 2013, São Paulo. Anais [...]. São Paulo: Unicamp, 2013. p. 950-954.

FILIPPO, D.; ROQUE, G.; PEDROSA, S. Pesquisa-ação: possibilidades para a Informática Educativa. In: JAQUES, Patrícia Augustin; PIMENTEL, Mariano; SIQUEIRA; Sean; BITTENCOURT, I. (org.) Metodologia de Pesquisa Científica em Informática na Educação: Concepção de Pesquisa. Porto Alegre: SBC, 2019. (Série Metodologia de Pesquisa em Informática na Educação, v.3). p. 1-29.

FOROUZAN, B. A. Comunicação de Dados e Redes de Computadores. Porto Alegre: Bookman, 2008.

FREITAS, V. C. B. Agente pedagógico animado para o ensino de redes de computadores no mundo virtual TCN5. 2017. Dissertação (Mestrado) - Universidade Federal de Santa Maria, Santa Maria, 2017.

GUERRA, E. L. de A. Manual da pesquisa qualitativa. Belo Horizonte: Grupo Anima Educação, 2014. Disponível em:

http://disciplinas.nucleoead.com.br/pdf/anima_tcc/gerais/manuais/manual_quali.pdf. Acesso em: 19 nov. 2018. 
HERPICH, F. et al. Jogos Sérios na Educação: Uma Abordagem para Ensino-Aprendizagem de Redes de Computadores (Fase I). In: Nuevas Ideas en Informática Educativa, 2013, Porto Alegre. Anais [...]. Porto Alegre: PUCRS, 2013. p. 617-620. Disponível em: http://www.tise.cl/volumen9/TISE2013/617-620.pdf. Acesso em: 22 ago. 2018.

HERPICH, F. ELAI: Intelligent agent adaptive to the level of expertise of students. 2015. Dissertação (Mestrado) - Universidade Federal de Santa Maria, Santa Maria, 2015.

JOCELEN, T. et al. Metodologia de ensino: aprendizagem baseada em projetos (PBL). In: Congresso Brasileiro de Educação em Engenharia, 2012, Belém do Pará. Anais [...]. Belém do Pará: Associação Brasileira de Educação em Engenharia, 2012. p. 1-10. Disponível em: http://www.abenge.org.br/cobenge/arquivos/7/artigos/104325.pdf. Acesso em: 5 nov. 2018.

KRASSMANN, A. L. Jogo sério ubíquo integrado a mundo virtual opensim para o ensino de redes de computadores (JASPION). 2016. Dissertação (Mestrado) - Universidade Federal de Santa Maria, Santa Maria, 2016.

LEAL, E. A.; MIRANDA, G. J.; CASA NOVA, S. P. Revolucionando a Sala de Aula: como envolver o estudante aplicando as técnicas de metodologias ativas de aprendizagem. São Paulo: Atlas, 2017.

MEC. Secretaria de Educação Profissional e Tecnológica (SETEC). Catálogo Nacional de Cursos Técnicos. Brasília, DF: Ministério da Educação, 2016. Disponível em: http://portal.mec.gov.br/index.php?option=com_docman\&view=download\&alias=77451cnct-3a-edicao-pdf-1\&category_slug=novembro-2017-pdf\&Itemid=30192. 10 abr. 2019.

MELGAÇO, A. C.; DIAS, J. Desenvolvimento e aplicação de práticas desplugadas para o ensino de Redes de Computadores. In: Workshop de Informática na Escola, 2019, Brasília. Anais [...]. Brasília: UnB, 2019. p. 481-490. Disponível em: https://www.brie.org/pub/index.php/wie/article/view/8539. Acesso em: 20 jun. 2020.

MORAN, J. Metodologias ativas para uma aprendizagem mais profunda. [s.l: 2013]. Disponível em: http://www2.eca.usp.br/moran/wpcontent/uploads/2013/12/metodologias_moran1.pdf. Acesso em: 01 nov. 2018.

MOREIRA, M. A. Aprendizagem Significativa: um conceito subjacente. In: Actas del encuentro internacional sobre el aprendizaje significativo, 1997, Burgos. Anais [...]. Burgos/ES, 1997. p. 19-44. Disponível em: https://www.if.ufrgs.br/ moreira/apsigsubport.pdf. Acesso em: 16 jul., 2019.

MOREIRA, M. A. Teorias de aprendizagem. São Paulo: EPU, 1999.

MOREIRA, M. A. et al. Teoria da Aprendizagem Significativa. In: Encontro Internacional Sobre Aprendizagem Significativa, 2000, Peniche. Anais [...]. Peniche, 2000. p. 33-45. Disponível em: https://www.if.ufrgs.br/ moreira/apsigcritport.pdf. Acesso em: 16 jul. 2019.

MOREIRA, M. A. Aprendizagem significativa em mapas conceituais. Porto Alegre:

UFRGS, 2012. Disponível em: https://www.if.ufrgs.br/ moreira/mapasport.pdf. 30 set. 2019.

MOREIRA, M. A. A teoria da aprendizagem significativa. 2. ed. Porto Alegre: UFRGS, 2016. Disponível em: https://www.if.ufrgs.br/ moreira/Subsidios6.pdf. 16 jul. 2019.

RESNICK, M. Sowing the seeds for a more creative society. Learning and Leading with Technology, p. 18-22, 2007. Disponível em: www.iste.org. 03 dez., 2019.

SANTOS, F. M. Análise de conteúdo: A visão de Laurence Bardin. Revista Eletrônica de Educação, v. 6, n. 1, p. 383-387, 2012. 
SANTOS, B. S. Dos. Ambiente de Ensino de Redes de Computadores Baseado em

Nuvem. 2017. Dissertação (Mestrado) - Universidade Federal do Maranhão, São Luis, 2017.

SCHWARTZ, M. Internet of Things with ESP8266. Birmingham: Packt Publishing, 2016.

TANENBAUM, A. S.; WETHERALL, D. J. Redes de Computadores. 5. ed. São Paulo: Pearson, 2011.

TAROUCO, L. M. R. Competências Digitais dos Professores. Pesquisa sobre o uso das tecnologias de informação e comunicação nas escolas brasileiras: TIC educação 2018. Núcleo de Informação e Coordenação do Ponto BR. São Paulo: Comitê Gestor da Internet no Brasil, 2019. Disponível em:

https://cetic.br/media/docs/publicacoes/216410120191105/tic_edu_2018_livro_eletronico.pdf . 10 jul. 2020.

VOSS, G. B. et al. Proposta de utilização de laboratórios virtuais para o ensino de redes de computadores: articulando ferramentas, conteúdos e possibilidades. RENOTE: Revista Novas Tecnologias, v. 10, n. 2, 2013. Disponível em:

http://www.seer.ufrgs.br/renote/article/view/36397. 22 ago., 2018.

VOSS, G. B.; NUNES, F. B.; MEDINA, R. D. Proposta de um jogo sério para o ensino de redes de computadores no ambiente virtual 3D OpenSim. In: Simpósio Brasileiro de Games, 2013, São Paulo. Proceedings [...]. 2013. São Paulo: Universidade Presbiteriana Mackenzie. p. 37-40. Disponível em:

http://www.sbgames.org/sbgames2013/proceedings/workshop/WorkshopVAR-11_Full.pdf. 22 ago. 2019.

Recebido em agosto de 2020.

Aprovado em novembro de 2020. 